\title{
Localized scleroderma: clinical spectrum and therapeutic update*
}

\author{
Mariana Figueiroa Careta ${ }^{1}$
}

Ricardo Romiti ${ }^{1}$

DOI: http://dx.doi.org/10.1590/abd1806-4841.20152890

\begin{abstract}
Scleroderma is a rare connective tissue disease that is manifested by cutaneous sclerosis and variable systemic involvement. Two categories of scleroderma are known: systemic sclerosis, characterized by cutaneous sclerosis and visceral involvement, and localized scleroderma or morphea which classically presents benign and self-limited evolution and is confined to the skin and/or underlying tissues. Localized scleroderma is a rare disease of unknown etiology. Recent studies show that the localized form may affect internal organs and have variable morbidity. Treatment should be started very early, before complications occur due to the high morbidity of localized scleroderma. In this review, we report the most important aspects and particularities in the treatment of patients diagnosed with localized scleroderma.
\end{abstract}

Keywords: Autoimmune diseases; Collagen diseases; Immune System Diseases; Epidemiology; Localized scleroderma; Signs and symptoms.

\section{INTRODUCTION}

Two categories of scleroderma are known: systemic sclerosis (SSc), characterized by cutaneous sclerosis and visceral involvement (especially the esophagus, lung and vascular system); and localized scleroderma (LoS), which classically presents benign and self-limited evolution and is confined to the skin and/or underlying tissues. Localized scleroderma or morphea is a chronic connective tissue disease of unknown etiology. ${ }^{1}$ Several types of morphea exist and each has different clinical manifestations and levels of connective tissue involvement (Chart 1). Morphea is characterized by skin thickening with increased quantities of collagen in the indurative lesion. ${ }^{2}$ This entity is subdivided into linear scleroderma, plaque morphea, deep morphea, bullous morphea, and generalized morphea. ${ }^{3,4,5}$ Each one of these subtypes may affect the face with varying intensity. LoS is the most common subtype of scleroderma in childhood. LoS categories are not mutually exclusive, since different subtypes may occur associated in the same patient.

LoS is a rare disease with an incidence of around 0.3 to 3 cases per 100,000 inhabitants/year. ${ }^{6}$ It is more common in Caucasian women, with a ratio of 2-4 women to 1 man. Prevalence is similar in children and adults..$^{6-9}$ The peak incidence occurs in the fifth decade of life in adults, whereas $90 \%$ of children are diagnosed between 2 and 14 years of age. . $^{811}$

The literature suggests that LoS is not an exclusively cutaneous disease. ${ }^{12}$ There is evidence of involvement of internal organs, association with other connective tissue diseases and exceptional transitional forms for SSc, especially in adults with the localized form of the disease. ${ }^{13,14}$

\section{CLASSIFICATION}

The most widely used classification in the literature is the Mayo Clinic Classification (in its simplified form), due to its objectivity and comprehensiveness. ${ }^{15}$ According to this classification, there are five groups LoS, namely:

1. Plaque morphea,

2. Generalized morphea,

3. Bullous morphea,

4. Linear scleroderma - including subtypes that involve the head and face, linear scleroderma 'en coup de saber' (LScs) and progressive facial hemiatrophy $(\mathrm{PFH})$,

5. Deep morphea.

Received on 24.06.2013.

Approved by the Advisory Board and accepted for publication on 11.10.2013.

* Study conducted at the Dermatology Department of the Hospital das Clinicas, Faculty of Medicine, University of São Paulo (HCFMUSP) - São Paulo (SP), Brazil. Conflict of interest: None

Financial Support: CNPq (National Council for Scientific and Technological Development), No.: 141992/2011-5.

University of São Paulo (USP) - São Paulo (SP), Brazil. 
CHART 1: Description of the different manifestations of localized scleroderma

\begin{tabular}{|c|c|c|c|c|}
\hline Classification & Subtypes & Features of lesions & Tissue involvement & Main location \\
\hline \multirow[t]{2}{*}{ Plaque morphea } & Superficial & Oval lesions & Limited to epidermis and dermis & Trunk \\
\hline & Deep & & $\begin{array}{l}\text { Deep induration } \\
\text { Dermis and SC tissue } \\
\text { Variable - fascia and muscle }\end{array}$ & \\
\hline \multirow[t]{3}{*}{ Linear morphea } & Trunk and limbs & Linear induration & $\begin{array}{l}\text { Dermis and SC tissue (may affect } \\
\text { bone and muscle) }\end{array}$ & Trunk and limbs \\
\hline & Head (LScs) & & $\begin{array}{l}\text { Frontoparietal dermis (muscle, bone } \\
\text { and CNS) }\end{array}$ & Face and scalp \\
\hline & $\mathrm{PFH}$ & & $\begin{array}{l}\text { Dermis, SC tissue, muscle, cartilage } \\
\text { and bone }\end{array}$ & \\
\hline Generalized morphea & & $\begin{array}{l}4 \text { or more indurated } \\
\text { plaques }>3 \mathrm{~cm}\end{array}$ & $\begin{array}{l}\text { Limited to the dermis and rare } \\
\text { in the SC tissue }\end{array}$ & $\begin{array}{l}\text { Diffuse (not on the } \\
\text { face or hands) }\end{array}$ \\
\hline Mixed morphea & & & Combination of 2 or more subtypes & \\
\hline
\end{tabular}

SC: subcutaneous; CNS: Central Nervous System

\section{LOCALIZED SCLERODERMA - SUBTYPES \\ Plaque morphea}

The most frequent form of LoS in adults is the plaque morphea, which is well-circumscribed and typically confined to the dermis. ${ }^{7,15,16,17}$ It is characterized by limited, round or oval shaped areas of hard and shiny skin, and affects one or more anatomical regions, most frequently the trunk and proximal extremities (Figure 1). In the earliest phases, a characteristic violaceous halo can be seen around the plaque ("purple ring"); this corresponds to the inflammatory phase of morphea.

\section{Bullous morphea}

Bullous morphea is a rare form of morphea characterized by the appearance of bullae or erosions on morphea plaques. ${ }^{18}$

\section{Deep morphea}

The subtype classified as 'deep morphea' usually manifests itself as a single lesion on the upper trunk, near the spine. ${ }^{19,20,21}$ The overlying skin may have a normal appearance, an atrophic appearance or be hardened, and will almost always be depressed or adhered to the deep plane. It is usually asymptomatic

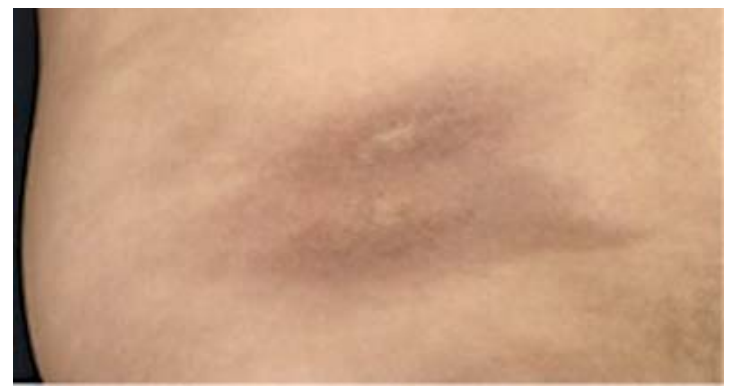

FIGURE 1: Plaque morphea lesion involving the trunk and is not associated with visceral involvement. ${ }^{22,23}$ Deep morphea is usually not preceded by clinical evidence of inflammation, skin discoloration or sclerosis (Figure 2). Some authors conclude that PFH may be considered a variety of deep linear scleroderma. ${ }^{22,24}$ Some cases of isolated deep morphea or similar injuries related to vaccine admnistration or intramuscular injection of vitamin $\mathrm{K}$ are described. ${ }^{25,26}$

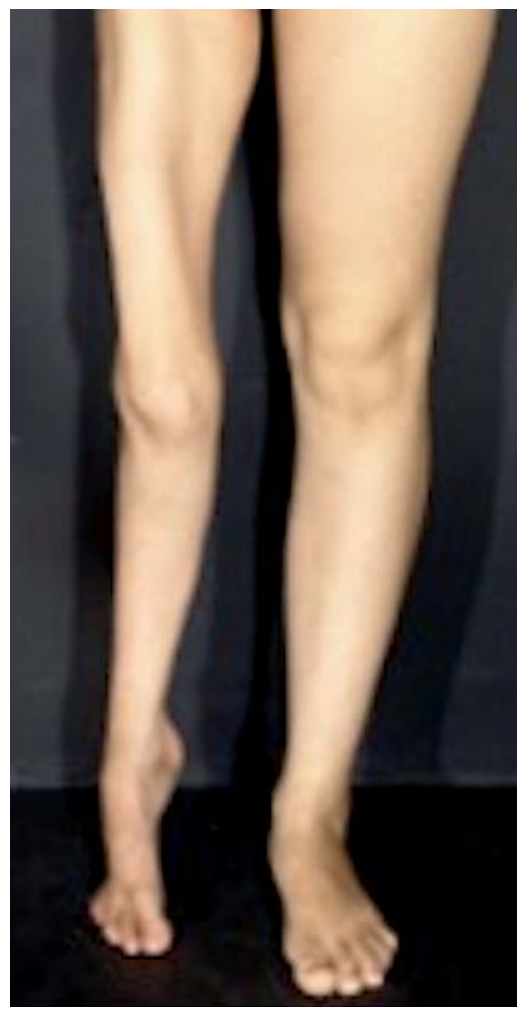

Figure 2:

Patient with deep morphea involving the right lower limb 


\section{Generalized morphea}

Generalized morphea is defined as morphea plaques involving more than 2 body sites. It is more frequent in women, and physical exercise has been cited as a triggering factor. The plaques are slightly inflamed, pigmented, ill-defined, thickened, adhered to deep planes, fascia and muscle, and most common on the trunk and extremities. Sclerosis onset is gradual and relatively fast over a period of months. Signs of acute inflammation such as edema and erythema may also be absent. ${ }^{27}$

Comprehensive literature review makes it possible to verify that clinical pictures similar to the clinical conditions described above are referred to indistinctly as generalized morphea and deep morphea. ${ }^{28,29,30}$ Both terms are used to describe the same clinical situation in which the sclerotic process fundamentally affects the deep dermis and adipose tissue, but also the fascia and superficial muscle in an extensive manner. The term 'generalized morphea' refers to the extension that fibrosis may achieve, while the term 'deep morphea' is intended to describe the histological findings of superficial muscle, fascia, adipose tissue and deep dermis involvement in a clinically localized way.

Generalized morphea is different from SSc. Patients may develop sclerosis of the fingers, but usually do not present ulcerations, phalanx resorption, changes in capillaries of the nail fold or Raynaud's phenomenon, which occur in the SSc. The face is generally spared. In addition, the presence of flexion contractures of the joints and muscle-joint manifestations are common. ${ }^{30}$ Pulmonary, esophageal, renal, or cardiac anomalies were occasionally documented. 7,9,11,12,30

\section{Linear scleroderma}

Linear scleroderma is characterized by one or more linear streaks of cutaneous induration that may involve dermis, subcutaneous tissue, muscle and underlying bone. Linear scleroderma is often observed in children and adolescents, and is the most frequent form of scleroderma in childhood, affecting $40-70 \%$ of the children studied. ${ }^{8,9,11}$ Approximately 67\% of patients with linear scleroderma are diagnosed before age 18 years. ${ }^{6}$ It is usually a single, unilateral lesion of linear distribution and involves the extremities, face or scalp. Lesions often follow Blaschko's lines (Figure 3).

Linear scleroderma may affect the muscles and underlying bones, causing growth disturbance and ankylosis. ${ }^{31,32}$ Children are more frequently affected than adults, but both sexes are affected equally. About $50 \%$ of patients with linear scleroderma have associated scleroderma in plaques. ${ }^{33}$ "Mixed" forms such as localized scleroderma of the face (LoSF) associated with plaque morphea or linear scleroderma in other areas (most often on the trunk) are a peculiar form found in children and rarely seen in adults. ${ }^{7}$ The duration of the disease is twice as long when LoS has an onset in childhood, and relapses and chronic disease activity are more frequently reported in these cases. ${ }^{7}$

LSF is not frequent. Jablonska et al. conducted a 20-year study of patients of the National Institute of Mexico City and found 30 patients dignosed with LSsc and 9 with PFH. ${ }^{34}$

When located on the scalp, it causes an alopecia plaque of linear distribution. The plaque is often atrophic and slightly depressed, and its skin is smooth, shiny, hard and sometimes pigmented. It is usually unilateral, affecting the parietal region, and it tends to deform the bone, causing depressed lesions described as LSsc. It may extend to the malar and nasal regions, and to the upper lip.

When the disorder completely affects the half of the face, it is classified as PFH or Parry-Romberg syndrome. ${ }^{35,36,37}$ The process causes atrophy of the entire adipose tissue, and muscle and bone deformity, with no apparent changes in the skin. Onset of disease usually occurs at a mean age of 11 years. The course of

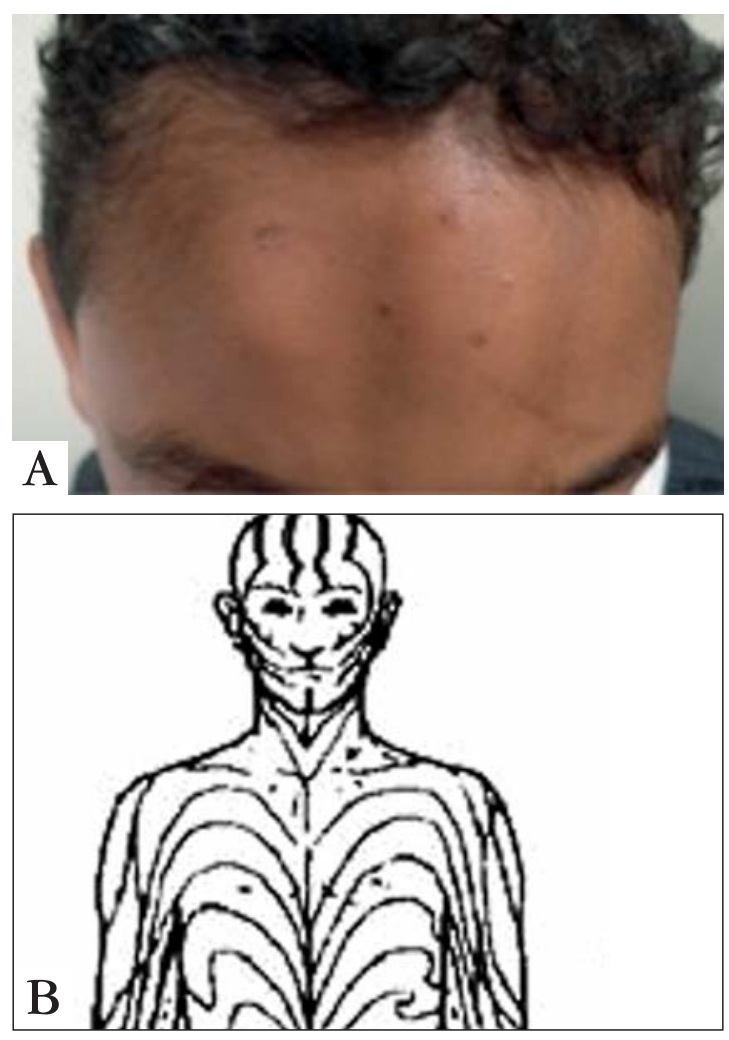

Figure 3: A. Patient with a linear scleroderma lesion (trilinear) on the forehead; B. Scheme of Blaschko's lines 
disease evolution takes place in a few years and is then followed by stabilization. There is a higher predominance in women (2-3:1).

High-severity was defined as presentation with pansclerotic or generalized morphea, LoSF and subtypes with evidence of high morbidity (e.g.: central nervous system involvement, extremity shortening, joint contracture). Moderate severity was defined as circumscribed deep morphea or linear scleroderma of the trunk or extremity without evidence of high morbidity. Low-severity patients are those with superficial circumscribed morphea (plaque lesions). ${ }^{38}$

\section{Linear scleroderma "en coup de sabre" (LScs)}

LScs is a rare and intriguing form of LoS, which was first described by Addison in $1854 .{ }^{39}$ It has a slowly progressive course and is generally limited to the hemiface. LScs lesions often start with contraction and stiffness of the affected area, forming a depressed groove on the parietal region and extending to the scalp, developing an area of linear alopecia (Figure 4). The groove may extend to the nasal region, upper lip and, sometimes, to the gingiva. The ipsilateral tongue may be atrophic and the spacing and direction of teeth may be altered. The jaw may be involved and the bones of the skull may be affected. In case of deformity of the jaw, it may result in poor dental occlusion, poor teeth implantation, tooth root atrophy and delayed appearance of teeth. ${ }^{37}$

It affects mainly children and is more predominant in females than males (3:1). There is a higher incidence at the menarche. The average age of onset is around 13 years of age and phase of activity of skin lesions usually lasts 2-5 years. ${ }^{10,32,40}$ Very little is known about its pathogenesis. Consequently, an effective therapy has not yet been found.

LScs is rarely associated with neurological and ophthalmological symptoms. ${ }^{41,42}$ However, the pediatric population presents more extracutaneous changes (especially orthopedic, ocular and neurological) than the adult population. ${ }^{8}$

LScs is usually unilateral, but rare bilateral cases have been reported. ${ }^{43-45}$

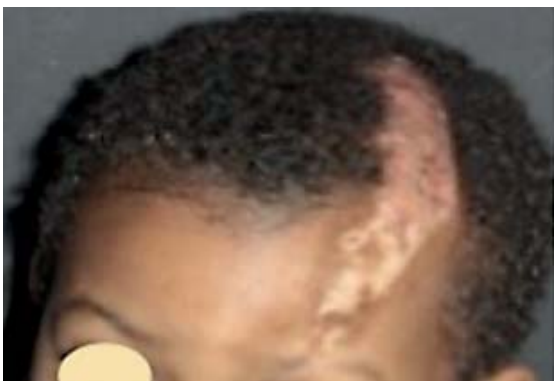

Figure 4

Patient with LScs

\section{Parry-Romberg Syndrome or Progressive facial hemiatrophy}

The progressive facial hemiatrophy $(\mathrm{PFH})$, also known as Parry-Romberg syndrome (PRS), was first described by Parry in 1825 and Romberg in 1846. It is rare disorder of unknown origin that usually develops between the first and second decades of life. ${ }^{46,47}$ The disease has a slow, self-limited progression and usually progresses for 2 to 20 years until it becomes stationary. It is characterized by unilateral atrophy of the skin, subcutaneous tissue, muscle and underlying bony structures, most commonly affecting dermatomes of one or multiple branches of the trigeminal nerve. Atrophy may be preceded by cutaneous induration and discoloration of the affected skin, such as depigmentation or hyperpigmentation and cicatricial alopecia may be observed in affected areas of the scalp. In most cases, skin inflammation, induration and adherence are absent or minimal. ${ }^{48,49,50}$ Involvement of the area below the eye region is more frequent (Figure 5).

PFH may be clinically very similar to LSsc, and they may coexist in about $20-37 \%$ of patients, which makes it difficult to distinguish between them. ${ }^{51,52}$ This percentage of coexistence is much higher than the one presented by LSsc with other forms of LS. ${ }^{37,49}$ However, the PFH does present skin sclerosis at any of its stages. ${ }^{46,47}$ Some authors have described patients with Lssc converting with time into $\mathrm{PFH}^{50,53-56}$ Age at the time of diagnosis is significant when the diagnosis is LSsc or PFH. Many authors consider LSsc and PFH to be the spectrum of a same disease. ${ }^{45,57}$ Wartenberg described LSsc as an abortive form of PFH, whereas Wolf and Ehrenclou believed that PFH is not a distinct disease but a syndrome that may coexist with linear scleroderma or occur as a sequela of various conditions. ${ }^{58,59} \mathrm{~A}$ histopathological criterion to distinguish both forms does not exist. ${ }^{45}$

Both LSsc and PFH may affect only the subcutaneous tissue (most often on the face) or affect the skin first and then the other deep tissues. ${ }^{60}$

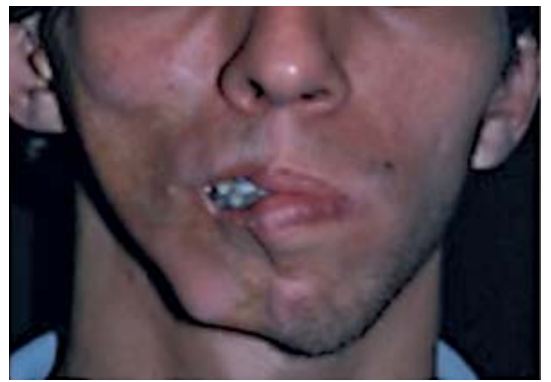

Figure 5: Patient with PFH 
Pronounced cases of PFH seem to be associated with relevant CNS involvement, which is observed in patients with early onset of the disease or a history of trauma preceding the lesion. ${ }^{24,36}$

About $30-40 \%$ of patients with PFH present changes typical of morphea or linear scleroderma off the face area. ${ }^{35,36,45,49}$

The frequency of neurological complications is around $20 \%$ and the frequency of ophthalmic complications is around $15 \%$. (Chart 2). ${ }^{8,36,37,61}$

\section{ETIOLOGY}

The pathogenesis of LSsc, PFH, LoS and SSc appear to be similar. There are references that indicate that it is triggered by viral or bacterial infection, such as by B. Burgdorferi. ${ }^{56,62,63}$ Other studies deny this association. ${ }^{60,64}$

Genetic factors have been implicated. ${ }^{56}$ However, it does not seem consistent, since only a $4.7 \%$ concordance between twins has been observed and family studies revealed only $1.6 \%$ frequency among first-degree relatives. ${ }^{65-67}$

Vascular abnormalities in scleroderma have also been reported. ${ }^{52}$ Some studies believe that cerebral calcifications associated with scleroderma of the face represent calcified hemangiomas. ${ }^{68}$ The presence of neurovasculitis was identified in different studies. ${ }^{24,69-73}$

Trauma is reported to act as an activator or initiator of PFH. ${ }^{24,74-77}$ Some studies, however, do not believe that trauma is a trigger or predictor of severity in PFH. ${ }^{60}$ The existence of bias cannot be ruled out due to the questioning about triggering factors to patients.

Since LSsc and PFH may involve the facial tissues and ipsilateral brain parenchyma, which have a share a common progenitor cell, there is a hypothesis of cortical dysgenesis, a malformation affecting one side of the rostral neural tube. ${ }^{78,79,80}$ Some characterize it as a neurocutaneous syndrome in which cutaneous manifestations are induced by primary brain malformations. ${ }^{54,55,70}$ A clone of vulnerable cells would develop the lesions following the Blaschko's lines. Thus, some speculate about the possibility of genetic mosaicism being a determining factor for the linear distribution of the sclerosis process. ${ }^{81}$ This theory would explain how multiple frontoparietal lesions may occur. ${ }^{82}$

Due to the description of skin lesions involving the area corresponding to the trigeminal nerve branches, Romberg suggested the disruption of sympathetic fibers as a possible etiology. ${ }^{50}$

Pathological evidence of intracerebral inflammation has already been illustrated in case reports with brain biopsy. $42,69,77,79,83$

Some changes that suggest autoimmune process are described as: elevation of antinuclear antibody; association with diseases such as LES, rheumatoid arthritis (RA) and SSc; association with transverse myelitis; and the presence of oligoclonal bands in CSF, with seizures and magnetic resonance imaging (MRI) showing brain lesions. ${ }^{84-87}$ Resolution and improvement with immunosuppressive therapy also support this theory. ${ }^{69,88,89}$

After extensive literature review, the inflammatory process with a probable autoimmune substrate and the embryological origin of the disease, such as the genetic mosaicism, seem to be more clearly associated with the etiopathogenesis in patients with LoSF. Available data suggest that the mechanism of pathogenesis of scleroderma is complex. Vessels, immune system and extracellular matrix are affected and may contribute to the development of the disease.

\section{EXTRACUTANEOUS MANIFESTATIONS}

The extracutaneous involvement in LoS is considered to be extremely unusual by many authors. . $2,13,3,2,56,57,90,91^{-1}$

Development of skin disease usually precedes systemic manifestations, which usually occur a few months after the onset of LoS. ${ }^{69,70}$ Systemic symptoms and signs may not occur in parallel with the cutaneous disease activity. ${ }^{70}$

The following extracutaneous involvements are described in patients with LoS: arthritis and other joint limitations, ocular involvement, neurological involvement, localized hair loss at the affected site, Raynaud's phenomenon, fascia or muscle involve-

Chart 2: Comparison of PFH and LSsc

\begin{tabular}{|c|c|c|}
\hline Findings & PFH & Scleroderma "en coup de sabre" \\
\hline \multirow[t]{6}{*}{ Face } & Unilateral atrophy & Unilateral, frontoparietal sclerotic band \\
\hline & Minimal or absent induration or previous inflammation & Usually preceded by skin induration \\
\hline & Cutaneous atrophy (normal hair and absent sclerosis) & Usually does not extend below the eyebrow \\
\hline & $\begin{array}{l}\text { Associated with dysplasia of the underlying bone, ton- } \\
\text { gue, gingiva and unilateral palate }\end{array}$ & $\begin{array}{l}\text { Important, depressed, hyperpigmented, shiny cutaneous scle- } \\
\text { rosis involving the scalp }\end{array}$ \\
\hline & & Frequently causes deformity and contractures \\
\hline & & Softening of lesions takes place over time \\
\hline
\end{tabular}


ment (documented by biopsy or imaging studies), gastroesophageal reflux (GERD), esophagitis (documented by upper gastrointestinal endoscopy), abnormal pulmonary function test (PFP), restrictive lung disease, cough or dyspnea, specific abnormalities on computed tomography (CT) or chest X-ray (CXR), vasculitis, arrhythmia, deep involvement of the breast tissue and others. ${ }^{7,44,92-94}$ Dentition changes are described in LSsc and PFH, and my lead to malocclusion as well as tongue atrophy., ${ }^{7,493}$

Over $20 \%$ of patients with LoS develop extracutaneous manifestations such as arthritis, seizures, and uveitis. ${ }^{11,17}$ Neurological complications are the most common association of systemic manifestations in LSsc. ${ }^{7,95}$

The most frequent neurological involvement associated with scleroderma are complex partial seizures. In $16 \%$ of cases neurological symptoms precede cutaneous manifestations and, apparently, there is no correlation with the severity of brain changes and skin

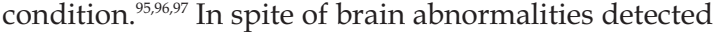
on imaging studies, neurologically asymptomatic patients are described. Brain abnormalities are ususally found to be ipsilateral to the skin lesions. ${ }^{71,72,88,89,95}$ The actual prevalence of neuroimaging abnormalities has not been determined. Neurological imaging examination is usually only performed in symptomatic patients and subclinical manifestations are often not diagnosed.

A study conducted at the Department of Dermatology of the Hospital das Clinicas, University of São Paulo, assessed radiological brain changes in 12 patients with localized scleroderma of the face by performing magnetic resonance imaging (MRI) of the skull, before and after 3 years of follow-up. Brain changes were found in $75 \%$ of the evaluated cases and there was no change or progression in radiological images after 3 years of follow-up. ${ }^{98}$

Ocular abnormalities reported in the literature were divided into: involvement of adnexal structures, anterior segment involvement, posterior segment involvement, and ocular-CNS involvement. ${ }^{36,61,73,99,100}$ Ocular involvement is not common in children with LoS, being present in about $3.2 \%$ of children and $10 \%$ of adults. Prevalence of ocular involvement is $14 \%$ in LScs, which affects the cephalic segment, and one third in patients with PFH. This manifestation usually has an early onset. ${ }^{61}$

In a study conducted by Christianson $\mathrm{HB}$ et al., Arthralgia was reported in $44 \%$ of 191 patients with plaque morphea and in $40 \%$ of 44 patients with generalized morphea. ${ }^{101}$ Several dermatological diseases, including lichen planus, vitiligo and alopecia areata have been associated with morphea. ${ }^{8}$

Due to the possible early onset and persistence of LoS for years, morbidity may be substantial.
Children with LoS have a higher risk of growth disturbance, including extremity length differences, joint contractures and facial atrophy. In a follow-up study of LoS patients with onset in childhood, $25 \%$ reported mild to moderate disability after 20 years. ${ }^{6}$ Another study of adults with childhood-onset LoS, more than $50 \%$ of patients reported permanent sequelae, including limited range of motion, deep tissue atrophy and extremity length differences. ${ }^{102}$

Therefore, orthopedic complications that interfere with mobility or cause severe joint contractures are common in linear scleroderma involving the limbs, especially in children. These are rarely observed when the disease begins in adulthood. ${ }^{7}$

In general, the greater the extension and depth of the sclerodermiform process, the greater is the likelihood of having an associated visceral anomaly. It occurs especially in the subtypes: linear scleroderma, generalized morphea and deep morphea.

Raynaud's phenomenon is usually associated with abnormal nail capillaroscopy, which suggests connective tissue disease. In a study conducted by Marzano et al. with 113 adult patients with LoS, Raynaud's phenomenon was found in $7 \%$ of the subjects. $87.5 \%$ of patients had positive antinuclear factor (ANF) and 50\% had anti-centromere antibody (ACA). Prevalence in the 126 children studied was found to be $2 \%{ }^{7}$

Raynaud's phenomenon is considered a risk factor for the development of systemic disease. Therefore, careful follow-up of these patients is mandatory. ${ }^{7}$

The incidence of autoimmune diseases and prevalence of autoantibodies are increased in patients with linear scleroderma, when compared with healthy control group. ${ }^{17}$ Cases of insulin-dependent diabetes mellitus (DM), Hashimoto's thyroiditis, Graves' disease and ulcerative colitis have been described ${ }^{8,103-105}$ It has also been reported that patients with morphea have an increased family risk of autoimmune disease. ${ }^{8,9}$

In a cohort study conducted by Zulian et al. the most frequent associations of extracutaneous manifestations found were: joint/neurological, ocular/neurological and Raynaud's phenomenon/joint. The authors recommend special attention in evaluating involvement of the joints, eyes and central nervous system in patients with LoS. ${ }^{17}$

The finding of more than one extracutaneous manifestation does not seem to represent a risk for development of SSc. Prevalence of evolution of linear scleroderma to SSc is around 0.9 to $1.3 \%{ }^{12,106}$ However, the disease seems to be more aggressive in patients with extracutaneous involvement than in those with cutaneous involvement alone, based on the presence of systemic inflammation and more frequent need for immunosuppressive therapy. In these patients, the 
involvement of organs is lighter than in SSc patients and poses no risk to life.

\section{LABORATORY CHANGES}

While in SSc certain serum changes (such as the presence of Scl-70) are considered markers of the disease, laboratory changes are variable in LoS and their relationship to the underlying disease is questionable. Topoisomerase 1 antibody, called Scl-70, is considered to be a serologic marker of SSc. ${ }^{7}$

The ACA (anti-centromere antibody) is considered a marker of the CREST syndrome, characterized by calcinosis, Raynaud's phenomenon, esophageal dysmotility, sclerodactyly, and telangiectasias.7

The number eosinophils and erythrocyte sedimentation rate (ESR) are found to be increased in case of disease activity or relapse. ${ }^{7}$

It is believed that ANF is positive in patients with mixed forms. When present in the LoSF, it would indicate more prolonged forms with complicated courses, but it is not correlated with disease activity. ${ }^{7}$ ANF with homogeneous and speckled pattern is positive in $37-50 \%$ of patients with linear scleroderma. ${ }^{6,32,56}$

Therefore, the presence of systemic markers such as ANF, ACA and Scl-70 is not always a sign of systemic disease. ${ }^{7,91}$ Autoantibodies such as centromere, Ro/La, RNP and Scl-70 may precede the development of systemic disease, and patients with these changes must be followed up for many years. ${ }^{56}$

The finding of rheumatoid factor (RF) is a risk factor for joint affection in patients with LoS. Positive RF cases should be monitored. ${ }^{17}$

Peripheral eosinophilia is commonly found in patients with generalized scleroderma, which may be very important. Increased gamma-globulin or immunological changes (such as the presence of ANF, antiDNA single chain), and decrease in complement or antiphospholipid antibody may also be found. ${ }^{30,33}$ Antihistone antibodies and increased procollagen type III serum levels have been proposed as indicators of severity in LoS. It is not uncommon to detect these anomalies in extensive and deep forms of morphea. ${ }^{107-109}$

\section{ANATOMICO-PATHOLOGICAL SKIN CHANGES}

Histology of scleroderma depends on two factors: stage of the disease and the depth to which the disease extends. In most situations, morphological changes are best seen in the transition area between the dermis and the subcutaneous tissue. Thus, the skin sample must contain subcutaneous tissue.

In the inflammatory phase or in the early lesions, which clinically exhibit erythematosus component, histology is not characteristic of scleroderma, and making a definitive diagnosis is difficult. In this phase, the presence of denser, homogenized collagen that is a little more eosinophilic, especially around vessels and adnexa is observed. The lymphohistiocytic inflammatory infiltrate with fibroblasts is periadnexal and perivascular, and the periadnexal fat cushion disappears or reduces. The colagen cords of newly formed collagen may already be seen invading the adipose tissue as pseudopods, and may be accompanied by inflammatory infiltrate. Both dermis and hypodermis vessels may show a tumefied endothelium with decreased lumen. ${ }^{1}$

In later lesions, scleroderma is installed and there is no clinical evidence of inflammation. It is characterized by intense fibrosis in the dermis, which progressively substitutes the adipose panicle. A definitive histological diagnosis is possible. At this stage, the dermal collagen is sclerotic, i.e., eosinophilic, homogenized and dense, and the inflammatory infiltrate is absent or discreetly confined around adnexae that already show atrophy. With the evolution of the disease, the tendency is that adnexae will be replaced by fibrosis (Figure 6). The vessels of the hypodermis show a thickened wall and significantly decreased lumen size. The replacement of adipose tissue by sclerotic collagen is best assessed when compared with a fragment of the contralateral normal skin. The destruction of the adipose tissue is clinically evidenced by the depression of the skin surface. ${ }^{2}$

In summary, scleroderma lesions are characterized by an initial inflammatory stage that is followed by a fibrosis stage and results in the replacement of normal dermis and hypodermis structures by abnormal collagen. ${ }^{10}$

\section{THERAPEUTICS}

The management of LoS is still unsatisfactory and there are very few randomized and controlled therapeutic studies. ${ }^{45}$ Different therapeutic modalities have been suggested, including the use of topical

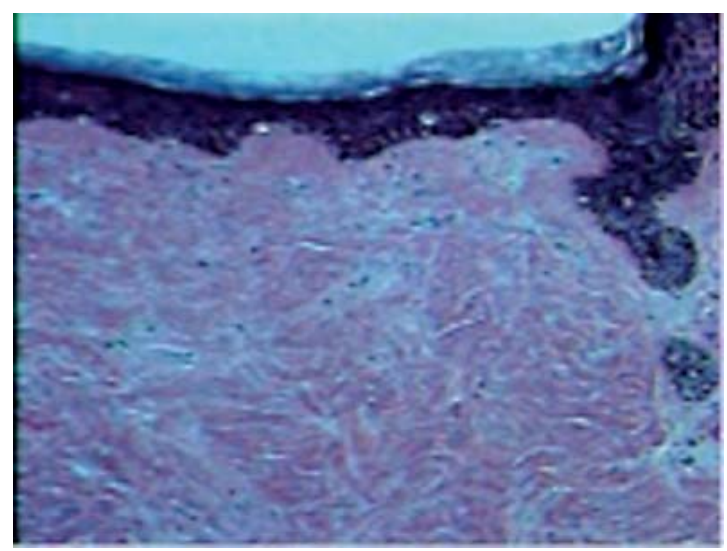

FIGURE 6: Histology of late-phase scleroderma 
medications, immunosuppressive pharmacological agents, physical therapy and phototherapy. ${ }^{110}$

Treatment should be initiated at an earlier stage before complications occur occur due to the high morbidity of localized scleroderma, which leads to limitation of motion and deformities. To start or indicate one treatment modality, we should consider the presence or absence of disease activity.

Criteria of disease activity include:

- Appearance of new lesions in the last 3 months (documented by the physician);

- Expansion of pre-existing lesion in the last three months (documented by the physician);

- Moderate or severe erythema or skin lesions with erythematous borders;

- Violaceous lesion or lesion border;

- Documentation of disease activity or progression to deep tissues by the doctor (by photography, MRI or ultrasonography (US);

- Increased induration of the lesion border;

- Worsening of hair loss on the scalp, eyebrows or eyelashes (documented by the physician);

- Increased creatine kinase (CK) in the absence of other changes;

- Skin biopsy demonstrating active disease.

The following parameters indicate clinical damage:

- Atrophy of the dermis;

- Atrophy of the subcutaneous tissue;

- Hyperpigmentation or hypopigmentation of the lesion;

- Lesion center with increased skin thickness.

Several clinical assessment methods have been published, such as the depigmentation, induration, erythema, and telangiectasia score; the modified Rodnan skin score (MRSS); and the Localized scleroderma Skin Severity Index (LoSSI). ${ }^{111-113}$ All these methods assess activity and damage together, based on limited clinical parameters. The lack of validation of treatment response criteria limits the ability of clinicians to judge the effectiveness of treatments.

Currently, there is no consensus on the treatment of LoS and a variety of therapeutic strategies have been proposed. Most of the studies are case series. There are very few comparative or placebo controlled studies. ${ }^{114-116}$ According to a study conducted by Li et al, in the United States and Canada in 2012, pediatric rheumatologists employ MTX or systemic corticosteroids to treat superficial, circumscribed morphea en plaque; dermatologists, on the other hand, usually prescribe topical agents and phototherapy to patients. $38,115,117-120$

Some therapeutic options are proposed for the treatment of LoS: D-penicillamine, topical or oral vita- min D, psoralen-UVA photochemotherapy, phenytoin, corticosteroids, methotrexate, cyclosporine and interferon. ${ }^{121-124}$

Several options are available for the topical treatment, which should be limited to more superficial and limited forms of morphea, such as plaque morphea. In the initial, more inflammatory phase, the use of high-potency topical corticosteroids is recommended. However, no study has demonstrated the real efficacy of this treatment. ${ }^{115}$

One pilot-controlled study with topical tacrolimus and including 10 patients with plaque morphea has been demonstrating efficacy. ${ }^{125}$ The use of topical imiquimod 3 times weekly has been shown effective in reducing erythema and induration of morphea plaques in a study with 12 patients and a report of 2 cases. ${ }^{111,126}$ The combination of calcipotriol with topical betamethasone has been demonstrated effective in a prospective study of 6 patients with plaque morphea. ${ }^{127}$

In an uncontrolled study, it was observed that scleroderma in children can be successfully treated with topical calcipotriol and low-dose UVA phototherapy. ${ }^{128}$

$\mathrm{Li}$ et al. established a consensus treatment plan (CTPs) for the first 12 months of activity of moderate to severe LoS. Based on scientific evidence, the plan only specifies the use of MTX or corticosteroids administered IV or orally. Mycophenolate mofetil (MMF) is suggested as an option for patients intolerant to MTX or who failed to respond to MTX. ${ }^{129}$ This consensus was based on indices of activity, damage and efficacy of treatment, and was guided by members of the CARRA (Childhood Arthritis and Rheumatology Research Alliance) ${ }^{92}$ Scheme is shown in chart 3. ${ }^{127-136}$

Thus, MTX can be used alone or in combination with oral or injectable corticotherapy. ${ }^{117,119,125,130-133}$ The recommended dose is $1 \mathrm{mg} / \mathrm{kg} /$ week, subcutaneously, and the maximum recommended dose is $25 \mathrm{mg} /$ week. $0.4-1 \mathrm{mg} /$ day or $5 \mathrm{mg} /$ week of folic acid should be supplemented to the diet. ${ }^{38}$

Most studies report an $80 \%$ improvement rate with this therapeutic regimen. ${ }^{130,131}$ Results were similar in patients treated with corticosteroids and MTX, when compared to those treated with MTX alone. The use of corticosteroids alone is effective, but the risk of relapse is higher. ${ }^{134}$

Recurrence rate ranges from 28 to $44 \%$ in $16-20$ months after discontinuation of MTX. In adults with onset in childhood, this recurrence rate is around $59 \% .{ }^{102,117,135}$ Continuously active disease was reported in $30 \%$ of adults with childhood-onset $\operatorname{LoS}^{102}$ and in $20 \%$ of patients with onset of LoS after 20 years of age. ${ }^{6}$

Based on its use in the treatment of LoS, other immunosuppressants are used in the treatment of morphea, such as D-penicillamine, which is little recommended owing to its poor safety profile. 
CHART 3: Comparison of PFH and LSsc

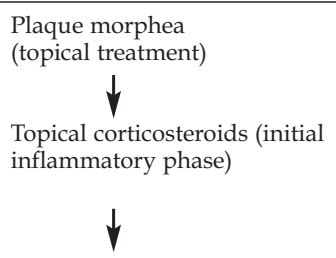

No response after 4-8 weeks

Topical tacrolimus

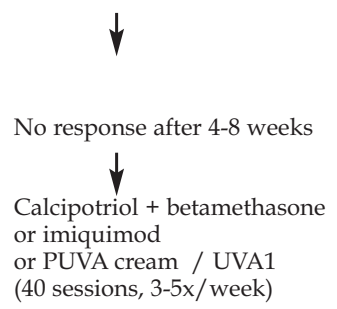

Generalized morphea

(without joint contractures)

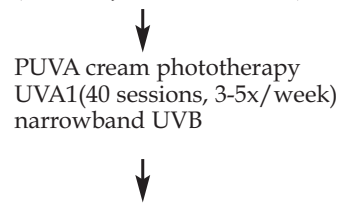

No response after 4-8 weeks

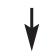

MTX: 15-25 mg/week +

Methylprednisolone $(30 \mathrm{mg} / \mathrm{K} \times 3$

days/month, 6 bolus) /

Prednisone $0.5-1 \mathrm{mg} / \mathrm{kg} /$ day

No response

Mycophenolate mofetil
Linear morphea

(face and limbs with possibility of contractures)

MTX: 15-25 mg/week +

Prednisone $0.5-1 \mathrm{mg} / \mathrm{kg} /$ day

Methylprednisolone (30mg/K $\times 3$ days/month, 6 bolus)

$\downarrow$

No response

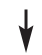

Mycophenolate mofetil

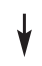

No response

PUVA cream phototherapy

UVA1(40 sessions, 3-5x/week)

narrowband UVB
Cyclosporine and extracorporeal photopheresis have isolated reports. ${ }^{136-138}$ Significant improvements in cases of generalized morphea have been reported with the use of infliximab (anti-TNF alpha antibody) and imatinib (tyrosine kinase inhibitor ). ${ }^{139,140}$

Another therapeutic option is the use of plastic surgery and physiatry techniques. Physical therapy is used in patients with sequelae from morphea (limited mobility of the extremities and joint contractures). No study demonstrates its actual utility. In any case, it does not seem to exacerbate the illness, therefore, it could be utilized in indicated cases. ${ }^{115}$

The management of facial atrophy, however, is challenging. Palliative reconstruction surgery is potentially beneficial for patients with disfiguring facial atrophy. The use of three-dimensional image may be useful in the preoperative period of bone reconstruction surgery. ${ }^{141}$

Ultraviolet radiation is an option that may be considered for the treatment of morphea. Possible options are: broadband ultraviolet light A (UVA combined or not with psoralen, narrowband UVA1 and UVB. The mechanism that could lead to a benefit in the management of morphea is unknown..$^{142,143}$ Experience with broadband UVA, associated or not with psoralens, is much smaller. A clinical improvement of $80 \%$ in treated patients has been reported..$^{143-45}$ Some authors suggest that treatment with PUVA (topical psoralen and UVA light) may be useful in the initial inflammatory stage of morphea. ${ }^{146}$ There is less experience is with narrowband UVB. Its effectiveness is most often referred to in isolated cases and there are few controlled studies. ${ }^{147}$

Morphea may present tendency to progress and recur use, especially when the onset of disease occurs in childhood. ${ }^{102}$ Nevertheless, LoS classically presents a self-limited course with a tendency to spontaneous regression after 3 to 5 years. ${ }^{101}$ Plaque morphea rarely progresses to generalized or debilitating forms. However, the uncertainty about the extent of involvement and progression of scleroderma lesions on the face require prompt therapeutic intervention in the presence of lesions at this site, in order to prevent damages to organs or internal structures and serious aesthetic impairment. ${ }^{148}$ Likewise, ELGS and HFP should always be treated early and intensively in order to minimize future sequelae. The use of various therapeutic options in the same patient throughout his life time is not uncommon. ${ }^{149}$

\section{CONCLUSION}

LoS seems not to be a exclusively cutaneous disease. When this disease is diagnosed, special attention should be taken to the involvement of internal organs, association with other connective tissue diseases and, more rarely, transitional forms to SSc. Treatment is challenging and difficult to evaluate as spontaneous regression of sclerotic lesions must always be considered. 


\section{REFERENCES}

1. Fitzpatrick TB, Eisen AZ, Wolff K, Freedberg IM, Austen KE, editors. Dermatology in General Medicine; 1987. p.1841-52.

2. Matsuura K, Umebayashi Y, Otsuka F. Computed tomography reveals thickened subcutaneous tissue in scleroderma. Br J Dermatol. 1997;137:1015-6.

3. Cassidy JT, Petty RE. The systemic scleroderma and related disorders. In: Cassidy JT, Petty RE, editors. Textbook of pediatric rheumatology. Philadelphia: W.B. Saunders; 2001. p. 505-34.

4. Nelson A. Localized slerodermas. In: Cassidy JT, Petty, RE, editors. Textbook of pediatric rheumatology. Philadelphia: W.B. Saunders; 2001. p. 535-44

5. Uziel Y, Miller ML, Laxer RM. Scleroderma in children. Pediatr Clin North Am. 1995;42:1171-203.

6. Peterson LS, Nelson AM, Su WP, Mason T, O'Fallon WM, Gabriel SE. The epidemiology of morphea (localized scleroderma) in Olmstead Country 1960-1993. J Rheumatol. 1997:24:73-80.

7. Marzano AV, Menni S, Parodi A, Borghi A, Fuligni A, Fabbri P, et al. Localized scleroderma in adults and children. Clinical and laboratory investigations on 239 cases. Eur J Dermatol. 2003:13:171-6.

8. Zulian F, Athreya BH, Laxer R, Nelson AM, Feitosa de Oliveira SK, Punaro MG, et al. Juvenile localized scleroderma: clinical and epidemiological features in 750 children. An international study. Rheumatology (Oxford). 2006;45:614-20.

9. Leitenberger JJ, Cayce RL, Haley RW, Adams-Huet B, Bergstresser PR, Jacobe HT. Distinct autoimune syndromes in morphea: a review of 245 adult and pediatric cases. Arch Dermatol. 2009;145:545-50.

10. Fett N, Werth VP. Update on morphea: part I. Epidemiology, clinical presentation, and pathogenesis. J Am Acad Dermatol. 2011:64:217-28.

11. Christen-Zaech S, Hakim MD, Afsar FS, Paller AS. Pediatric morphea (localized scleroderma): review of 136 patients. J Am Acad Dermatol. 2008;59:385-96.

12. Dehen L, Roujeau JC, Cosnes A, Revuz J. Internal involvement in localized scleroderma. Medicine (Baltimore). 1994;73:241-5.

13. Birdi N, Laxer RM, Thorner P, Fritzler MJ, Silverman ED. Localized scleroderma progressing to systemic disease: case report and review of the literature. Arthritis Rheum. 1993:36:410-5.

14. Mayorquin FJ, McCurley TL, Levernier JE, Myers LK, Becker JA, Graham TP, et al. Progression of childhood linear scleroderma to fatal systemic sclerosis. Rheumatol. 1994;21:1955-7.

15. Peterson LS, Nelson AM, Su WP. Classification of Morphea (Localized Scleroderma). Mayo Clin Proc. 1995;70:1068-76.

16. Nelson A. Localized scleroderma including morphea, linear scleroderma, and eosinophilic fasciitis. Curr Probl Pediatr. 1996;26:318-24.

17. Zulian F, Vallongo C, Woo P, Russo R, Ruperto N, Harper J, et al. Localized Scleroderma in Childhood is not just a skin disease. Arthritis Rheum. 2005;52:2873-81

18. Trattner A, David M, Sandbank M. Bullous morphea: a distinct entity. Am J Dermatopathol. 1994;16:414-7.

19. Kobayashi KA, Lui H, Prendiville JS. Solitary morphea profunda in a 5-year-old girl: case report and review of the literature. Pediatr Dermatol. 1991;8:292-5

20. Kirsner RS, Pardes JB, Falanga V. Solitary fibrosing paraspinal plaque: solitary morphea profunda. Br J Dermatol. 1993;128:99-101.

21. Azad J, Dawn G, Shaffrali FC, Holmes SC, Barnetson RJ, Forsyth A. Does solitary morphea profunda progress? Clin Exp Dermatol. 2004:29:25-7.

22. Blaszczyk M, Krysicka-Janiger K, Jabłońska S. Primary atrophic profound linear scleroderma. Dermatology. 2000:200:63-6.

23. Malandrini A, Dotti MT, Federico A. Selective ipsilateral neuromuscular involvement in a case of facial and somatic hemiatrophy. Muscle Nerve. 1997;20:890-2.

24. Blaszczyk M, Jablonska S. Linear scleroderma en coup de sabre. Relationship with progressive facial hemiatrophy (PFH). Adv Exp Med Biol. 1999;455:101-4.

25. Torrelo A, Suárez J, Colmenero I, Azorín D, Perera A, Zambrano A. Deep morphea after vaccination in two young children. Pediatr Dermatol. 2006;23:484-7.

26. Morell A, Betlloch I, Sevila A, Bañuls J, Botella R. Morphea-like reaction from vitamin K1. Int J Dermatol. 1995;34:201-2.

27. Daoud MS, Su WP, Leiferman KM, Perniciaro C. Bullous morphea: clinical pathologic and immunopathologic evaluation of 13 cases. J Am Acad Dermatol. 1994;30:937-43

28. Su WPD, Person JR. Morphea profunda. A new concept and a histopathologic study of 23 cases. Am J Dermatopathol. 1981:3:251-60.

29. Park JH, Lee CW. Concurrent development of dermatomyositis and morphea profunda. Clin Exp Dermatol. 2002;27:324-7.

30. Bielsa I, Cid M, Herrero C, Cardellach F. Generalized morphea: systemic aspects of a cutaneous disease. Description of 12 cases and review of the literature. Med Clin (Barc). 1985;85:171-4.

31. Hatzis JA, Stratigos AJ, Dimopoulos JC, Tzermias CK, Orfanidou A, Bassioukas $\mathrm{KC}$. Linear scleroderma with severe leg deformity. Australas J Dermatol.
1992:33:155-7.

32. Tuffanelli DL. Localized scleroderma. Semin Cutan Med Surg. 1998;17:27-33.

33. Falanga V, Medsger TA Jr, Reichlin M. Antinuclear and anti-single-stranded DNA antibodies in morphea and generalized morphea. Arch Dermatol. 1987;123:350-3

34. Jablonska S, Blaszczyk M. Long-lasting follow-up favours a close relationship between progressive facial hemiatrophy and scleroderma en coup de sabre. J Eur Acad Dermatol Venereol. 2005:19:403-4.

35. Orozco-Covarrubias L, Guzmán-Meza A, Ridaura-Sanz C, Carrasco Daza D, Sosade-Martinez C, Ruiz-Maldonado R. Scleroderma "en coup de sabre" and progressive facial hemiatrophy. Is it possible to differentiate them? J Eur Acad Dermato Venereol. 2002;16:361-6.

36. Blaszczyk M, Królicki L, Krasu M, Glinska 0, Jablonska S. Progressive facial hemiatrophy: central nervous system involvement and relationship with scleroderma en coup de sabre. J Rheumatol. 2003:30:1997-2004.

37. Tollefson MM, Witman PM. En coup de sabre morphea and Parry-Romberg syndrome: a retrospective review of 54 patients. J Am Acad Dermatol. 2007;56:257-63.

38. Li SC, Feldman BM, Higgins GC, Haines KA, Punaro MG, O'Neil KM. Treatment of pediatric localized scleroderma: results of a survey of North American pediatric rheumatologists. J Rheumatol. 2010;37:175-81.

39. Addison $\mathrm{CH}$. Medico-chirurgical transactions of 1854 quoted by Fox TC: note on the history of scleroderma in England. Br J Dermatol. 1892;4:101.

40. Chiang KL, Chang KP, Wong TT, Hsu TR. Linear scleroderma "en coup de sabre": initial presentation as intractable partial seizures in a child. Pediatr Neonatol. 2009;50:294-8.

41. Chung MH, Sum J, Morrell MJ, Horoupian DS. Intracerebral involvement in scleroderma en coup de sabre: report of case with neuropathologic findings. Ann Neurol. 1995;37:679-81.

42. Lüer W, Jöckel D, Henze T, Schipper HI. Progressive inflammatory lesions of the brain parenchyma in localized scleroderma of the head. J Neurol. 1990;237:379-81.

43. Ostertag JU, Hulsmans RF, Neumann HA. Bilateral tempoparietal scleroderma "en coup de sabre". Hautarzt. 1994;45:398-401.

44. Rai R, Handa S, Gupta S, Kumar B. Bilateral En Copu de Sabre - A Rare Entity. Pediatr Dermatol. 2000;17:222-4.

45. Gambichler T, Kreuter A, Hoffmann K, Bechara FG, Altmeyer P, Jansen T. Billateral linear scleroderma "en coup de sabre" associated with facial atrophy and neurological complications. BMC Dermatol. 2001;1:9.

46. Parry CH. Collections from unpublished papers. London: Underwood; 1825 . p. 178

47. Romberg MH. Trophoneurosen. In: Romberg MH. Klinische ergebnisse. Berlin: Forstner; 1946. p.75-81.

48. Jappe U, Hölzle E, Ring J. Parry Romberg syndrome. Review and new observations based on a case with unusual features. Hautarzt. 1996;47:599-603.

49. Jablonska S, Blaszczyk M, Rosinska D. Progressive facial hemiatrophy and scleroderma en coup de sabre: clinical presentation and course as related to the onset in early childhood and young adults. Arch Argent Dermatol. 1998;48:125-8.

50. Lehmann TJA. The Parry- Romberg syndrome of progressive facial hemiatrophy and linear scleroderma en coup de sabre. Mistaken diagnosis or overlaping conditions? J Rheumatol. 1992:19:844-5.

51. DeFelipe J, Segura T, Arellano Jl, Merchán A, DeFelipe-Oroquieta J, Martín P, et al. Neuropathological findings in a patient with epilepsy and the Parry-Romberg syndrome. Epilepsia. 2001;42:1198-203

52. Woolfenden AR, Tong DC, Norbash AM, Albers GW. Progressive facial hemiatrophy: Abnormality of intracranial vasculature. Neurology. 1998;50:1915-7.

53. Cory RC, Clayman DA, Faillace WJ, McKee SW, Gama CH. Clinical and radiologic findings in progressive facial hemiatrophy (Parry-Romberg syndrome). AJNR Am J Neuroradiol. 1997:18:751-7.

54. Taylor HM, Robinson R, Cox T. Progressive facial hemiatrophy: MRI appearances. Dev Med Child Neurol. 1997;39:484-6.

55. Goldenstein-Schainberg C, Pereira RM, Gusukuma MC, Messina WC, Cossermell W. Childhood linear scleroderma "en coup de sabre" with uveitis. J Pediatr. 1990;117:581-4

56. Blaszczyk M, Janniger CK, Jablonska S. Childhood scleroderma and its peculiarites. Cutis. 1996;58:141-4, 148-52.

57. Vierra E, Cunningham BB. Morphea and localized scleroderma in children. Semin Cutan Med Surg. 1999:18:210-25.

58. Wartenberg R. Progressive facial hemiatrophy. Arch Neurol Psychiatry 1945;54:75-96.

59. Wolf HG, Ehrenclou AH. Trophic disorders of central origin: report of a case of progressive facial hemiatrophy associated with a lipodistrophy and other metabolic derangements. JAMA. 1927;88:991-4.

60. Sommer A, Gambichler T, Bacharach-Buhles M, von Rothenburg T, Altmeyer P, Kreuter A. Clinical and serological characteristics of progressive facial hemiatrophy: A case series of 12 patients. J Am Acad Dermatol. 2006;54:227-33.

61. Zannin ME, Martini G, Athreya BH, Russo R, Higgins G, Vittadello F, et al. Ocula involvement in children with localised scleroderma: a multi-centre study. $\mathrm{Br}$ 
Ophthalmol. 2007:91:1311-4.

62. Sahin MT, Bariş S, Karaman A. Parry-Romberg syndrome: a possible association with borreliosis. J Eur Acad Dermatol Venereol. 2004;18:204-7.

63. Emery H. Pediatric scleroderma. Semin Cutan Med Surg. 1998;17:41-7.

64. Esgleyes-Ribot T, García-De la Torre I, Gonzalez-Mendoza A, Guerrerosantos J, Barceló R. Progressive facial hemiatrophy (Parry-Romberg syndrome) and antibodies to Borrelia. J Am Acad Dermatol. 1991;25:578-9.

65. Feghali-Bostwick C, Medsger TA Jr, Wright TM. Analysis of systemic sclerosis in twins reveals low concordance for the presence of antinuclear antibodies. Arthritis Rheum. 2003;48:1956-63.

66. Katsumoto TR, Whitfield ML, Connolly MK. The patogenesis of systemic sclerosis. Annu Rev Pathol. 2011;6:509-37.

67. Arnett FC, Cho M, Chatterjee S, Aguilar MB, Reveille JD, Mayes MD. Familial occurrence frequencies and relative risks for systemics sclerosis (Scleroderma) in three United States cohorts. Arthritis Rheum. 2001;44:1359-62.

68. Asher SW, Berg BO. Progressive hemifacial atrophy. Report of three cases, including one observed over 43 years and computed tomographic findings. Arch Neurol. 1982;39:44-6.

69. Stone J, Franks AJ, Guthrie JA, Johnson MH. Scleroderma "en coup de sabre": pathological evidence of intracerabral inflammation. J Neurol Neurosurg Psychiatry. 2001;70:382-5.

70. Menni S, Marzano AV, Passoni E. Neurologic abnormalities in two patients with facial hemiatrophy and sclerosis coexisting with morphea. Pediatr Dermatol. 1997;14:113-6.

71. Appenzeller S, Montenegro MA, Dertkigil SS, Sampaio-Barros PD, Marques-Neto $\mathrm{JF}$, Samara AM, et al. Neuroimaging findings in scleroderma en coup de sabre. Neurology. 2004;62:1585-9.

72. Holland KE, Steffes B, Nocton JJ, Schwabe MJ, Jacobson RD, Drolet BA. Linear cleroderma en coup de sabre with associated neurologic abnormalities. Pediatrics. 2006;117:e132-6.

73. Holl-Wieden A, Klink T, Klink J, Warmuth-Metz M, Girschick HJ. Linear scleroderma "en coup de sabre" associated with cerebral and ocular vasculitis. Scand $J$ Rheumatol. 2006;35:402-4.

74. Fry JA, Alvarellos A, Fink CW, Blaw ME, Roach ES. Intracranial findings in progressive facial atrophy. J Rheumatol. 1992;19:956-8.

75. Yamanaka CT, Gibbs NF. Trauma-induced linear scleroderma. Cutis. 1999;63:29-32.

76. Komócsi A, Tóvári E, Kovács J, Czirják L. Physical injury as a provoking fator in three patients with scleroderma. Clin Exp Rheumatol. 2000;18:622-4.

77. Pupillo G, Andermann F, Dubeau F. Linear scleroderma and intractable epilepsy: neuropathologic evidence for a chronic inflamatory process. Ann Neurol. 1996;39:277-8.

78. Dupont S, Catala M, Hasboun D, Semah F, Baulac M. Progressive facial hemiatrophy and epilepsy. Neurology. 1997;48:1013-8.

79. Terstegge K, Kunath B, Felber S, Speciali JG, Henkes H, Hosten N. MR of brain involvement in progressive facial hemiatrophy (Romberg disease): Reconsideration of a syndrome. AJNR Am J Neuroradiol. 1994;15:145-50.

80. Nüssgens Z, Roggenkämper P. Congenital facial hemiatrophy. Report of two pediatric cases. Klin Monbl Augenheilkd. 1992;201:119-21.

81. Weibel L, Harper Jl. Linear morphea follows Blaschko's lines. Br J Dermatol. 2008; 159:175-81.

82. Soma Y, Fujimoto M. Frontoparietal scleroderma "en coup de sabre" following Blaschko's lines. J Am Acad Dermatol. 1998;38:366-8.

83. Grosso S, Fioravanti A, Biasi G, Conversano E, Marcolongo R, Morgese G, et al. Linear scleroderma associated with progressive brain atrophy. Brain Dev. 2003:25:57-61.

84. Garcia-de la Torre I, Castello-Sendra J, Esgleyes-Ribot T, Martinez-Bonilla G, Guerrerosantos J, Fritzler MJ. Autoantibodies in Parry-Romberg syndrome: a serological study of 14 patients. J Rheumatol. 1995;22:73-7.

85. Stone J. Parry-Romberg syndrome: a global survey of 205 patients using the internet. Neurology. 2003;61:674-6

86. Kanzato N, Matsuzaki T, Komine Y, Saito M, Saito A, Yoshio T, et al. Localized scleroderma associated with progressing ischemic stroke. J Neurol Sci. 1999;163:86-9.

87. Littman B. Linear scleroderma: a response to neurological injury? Report and literature review. J Rheumatol. 1989;16:1135-40.

88. Goldberg-Stern H, deGrauw T, Passo M, Ball WS Jr. Parry Romberg syndrome: Follow up imaging during supressive therapy. Neuroradiology. 1997;39:873-6.

89. Unterberger I, Trinka E, Engelhardt K, Muigg A, Eller P, Wagner M, et al. Linear scleroderma "en coup de sabre" coexisting with plaque-morphea: neuroradiological manifestation and response to corticosteroids. J Neurol Neurosurg Psychiatry. 2003;74:661-4.

90. Krafchik BR. Localized cutaneous scleroderma. Semin Dermatol. 1992;11:65-72.

91. Jablonska S, Blaszczyk M, Chorzelski TP, Jarzabek-Chorzelska M, Kumar V, Beutner EH. Clinical relevance of immunologic findings in scleroderma. Clin Dermatol. 1992;10:407-21.
92. Li SC, Torok KS, Pope E, Dedeoglu F, Hong S, Jacobe HT, et al. Development of Consensus Treatment Plans for Juvenile Localized Scleroderma: A Roadmap Toward Comparative Effectiveness Studies in Juvenile Localized Scleroderma. Arthritis Care Res (Hoboken). 2012;64:1175-85.

93. Itin PH, Schiller P. Double-lined frontparietal scleroderma en coup de sabre. Dermatology. 1999;199:185-6.

94. Sandhu K, Handa S. Subdural hygroma in a patient with Parry-Romberg syndrome. Pediatr Dermatol. 2004;21:48-50.

95. Liu P, Uziel Y, Chuang S, Silverman E, Krafchik B, Laxer R. Localized scleroderma: Imaging fetures. Pediatr Radiol. 1994;24:207-9.

96. Kister I, Inglese M, Laxer RM, Herbert J. Neurologic manifestations of localized scleroderma. A case report and literature review. Neurology. 2008;71:1538-45.

97. Nadeau SE. Neurologic manifestations of connective tissue disease. Neurol Clin. 2002;20:151-78, vi.

98. Careta MF1, Leite Cda C, Cresta F, Albino J, Tsunami M, Romiti R. Prospective study to evaluate the clinical and radiological outcome of patients with scleroderma of the face. Autoimmun Rev. 2013;12:1064-9.

99. Suttorp-Schulten MS, Koornneef L. Linear scleroderma associated with ptosis and motility disorders. Br J Ophthalmol. 1990;74:694-5.

100. Obermoser G, Pfausler BE, Linder DM, Sepp NT. Scleroderma en coup de sabre with central nervous system and ophthalmologic involvement: treatment of ocular symptoms with interferon gamma. J Am Acad Dermatol. 2003;49:543-6.

101. Christianson HB, Dorsey CS, Kierland RR, O'Leary PA. Localized scleroderma: a clinical study of two hundred thirty-five cases. AMA Arch Derm. 1956;74:629-39.

102. Saxton-Daniels $\mathrm{S}$, Jacobe HT. An evaluation of long-term outcomes in adults with pediatric-onset morphea. Arch Dermatol. 2010;146:1044-5.

103. Lee HJ, Kim MY, Ha SJ, Kim JW. Two cases of morphea associated with Hashimoto's thyroiditis. Acta Derm Venereol. 2002;82:58-9.

104. Dervis E, Acbay O, Barut G, Karaoglu A, Ersoy L. Association of vitiligo, morphea and Hashimoto's thyroiditis. Int J Dermatol. 2004;43:236-7.

105. Finkelstein E1, Amichai B, Metzker A. Coexistence of vitiligo and morphea: a case report and review of the literature. J Dermatol. 1995;22:351-3.

106. De P, Lloyd HJ, Rashid AM, Anstey AV. Morphea presenting shortly after the onset of Schmidt's syndrome. Clin Exp Dermatol. 2000;25:168-9.

107. Sato S, Fujimoto M, Ihn H, Kikuchi K, Takehara K. Clinical characteristics associated with antihistone antibodies in patients with localized scleroderma. J Am Acad Dermatol. 1994;31:567-71

108. Parodi A, Drosera M, Barbieri L, Rebora A. Antihistone antibodies in scleroderma. Dermatology. 1995;191:16-8.

109. Kikuchi K, Sato S, Kadono T, Ihn H, Takehara K. Serum concentration of procollagen type I carboxyterminal propetide in localized scleroderma. Arch Dermatol. 1994:130:1269-72.

110. Hunzelmann N, Scharffetter Kochanek K, Hager C, Krieg T. Management of localized scleoderma. Semin Cutan Med Surg. 1998;17:34-40.

111. Dytoc M, Ting PT, Man J, Sawyer D, Fiorillo L. First case series on the use of imiquimod for morphea. Br J Dermatol. 2005;153:815-20.

112. Clements P, Lachenbruch P, Siebold J, White B, Weiner S, Martin R, et al. Inter and intraobserver variability of total skin thickness score (modified Rodnan TSS) in systemic sclerosis. J Rheumatol. 1995;22:1281-5.

113. Arkachaisri T, Pino S. Localized scleroderma severity index and global assessments: a pilot study of outcome instruments. J Rheumatol. 2008:35:650-7.

114. Chung L, Lin J, Furst DE, Fiorentino D. Systemic and localized scleroderma. Clin Dermatol. 2006:24:374-92.

115. Fett N, Werth VP. Update on morphea: part II. Outcome measures and treatment. J Am Acad Dermatol. 2011;64:231-42.6

116. Vilela FA1, Carneiro S, Ramos-e-Silva M. Treatment of morphea or localized scleroderma: review of the literatura. J Drugs Dermatol. 2010;9:1213-9.

117. Weibel L, Sampaio MC, Visentin MT, Howell KJ, Woo P, Harper Jl. Evaluation of methotrexate and corticosteroids for the treatment of localized scleroderma (morphea) in children. Br J Dermatol. 2006;155:1013-20.

118. Zulian F, Martini G, Vallongo C, Vittadello F, Falcini F, Patrizi A, et al. Methotrexate treatment in juvenile localized scleroderma: a randomized, double-blind, placebocontrolled trial. Arthritis Rheum. 2011;63:1998-2006.

119. Uziel Y, Feldman BM, Krafchik BR, Yeung RS, Laxer RM. Methotrexate and corticosteroid therapy for pediatric localized scleroderma. J Pediatr. 2000;136:91-5.

120. Zwischenberger B, Jacobe H. A systematic review of morphea treatments and therapeutic algorithin. J Am Acad Dermatol. 2011;65:925-41.

121. Cunningham BB, Landells ID, Langman C, Sailer DE, Paller AS. Topical calcipotriene for morphea/linear scleroderma. J Am Acad Dermatol. 1998;39:211-5.

122. Hulshof MM, Bouwes Bavinck JN, Bergman W, Masclee AA, Heickendorff L, Breedveld FC, et al. Double-blind, placebo-controlled study of oral calcitriol for treatment of localized and systemic scleroderma. J Am Acad Dermatol. 2000:43:1017-23.

123. Elst EF, Van Suijlekom-Smit LW, Oranje AP. Treatment of linear scleroderma with 
oral 1,25-ddihydroxyvitamin D3 (calcitriol) in seven children. Pediatr Dermatol. 1999;16:53-8.

124. Higashi Y, Kanekura T, Fukumaru K, Kanzaki T. Scleroderma en Coup de Sabre with Central Nervous System Involvement. J Dermatol. 2000;27:486-8.

125. Kroft EB, Groeneveld TJ, Seyger MM, de Jong EM. Efficacy of topical tacrolimus $0,1 \%$ in active plaque morphea: randomized, double-blind, emoliente-controlled pilot study. Am J Clin Dermatol. 2009:10:181-7.

126. Campione E, Paternò EJ, Diluvio L, Orlandi A, Bianchi L, Chimenti S. Localized morphea treated with imiquimod $5 \%$ and dermoscopic assessment of effectiveness. J Dermatolog Treat. 2009;20:10-3.

127. Dytoc MT, Kossintseva I, Ting PT. First case series on the use of calcipotriol-betamethasone dipropionate for morphea. Br J Dermatol. 2007;157:615-8.

128. Kreuter A, Gambichler T, Avermaete A, Jansen T, Hoffmann M, Hoffmann K, et al. Combined treatment with calcipotriol ointment and low-dose ultravioleta A I phototherapy in childhood morphea. Pediatr Dermatol. 2001;18:241-5.

129. Martini G, Ramanan AV, Falcini F, Girschick H, Goldsmith DP, Zulian F. Sucessfu treatment of severe or methotrexate resistant juvenile localized scleroderma with mycophenolate mofetil. Rheumatology (Oxford). 2009;48:1410-3.

130. Seyger MM, van den Hoogen FH, de Boo T, de Jong EM. Low-dose methotrexate in the treatment of widespread morphea. J Am Acad Dermatol. 1998;39:220-5.

131. Kreuter A, Gambichler T, Breuckmann F, Rotterdam S, Freitag M, Stuecker M, et al. Pulsed high-dose corticosteroids combined with low-dose methotrexate in severe localized scleroderma. Arch Dermatol. 2005;141:847-52.

132. Fitch PG1, Rettig P, Burnham JM, Finkel TH, Yan AC, Akin E, Cron RQ. Treatment of pediatric localized scleroderma with methotrexate. J Rheumatol. 2006;33:609-14.

133. Cox D, O' Regan G, Collins S, Byrne A, Irvine A, Watson R. Juvenile localized scleroderma: a retrospective review of response to systemic treatment. Ir J Med Sci. 2008; 177:343-6.

134. Joly P, Bamberger N, Crickx B, Belaich S. Treatment of severe forms of localized scleroderma with oral corticosteroids: folow-up study on 17 patients. Arch Dermatol. 1994;130:663-4.

135. Mirsky L, Chakkittakandiyil A, Laxer RM, O'Brien C, Pope E. Relapse after systemic treatment in pediatric morphea. Br J Dermatol. 2012;166:443-5.

136. Pérez Crespo M, Betlloch Mas I, Mataix Díaz J, Lucas Costa A, Ballester Nortes I. Rapid response to cyclosporine and maintenance with methotrexate in linear scleroderma in a young girl. Pediatr Dermatol. 2009;26:118-20.

137. Neustadter JH, Samarin F, Carlson KR, Girardi M. Extracorporeal photochemotherapy for generalized deep morphea. Arch Dermatol. 2009;145:127-30.

138. Schlaak M, Friedlein H, Kauer F, Renner R, Rogalski C, Simon JC. Sucessful therapy of a patient with therapy recalcitrant generalized bullous scleroderma by extracorporal photopheresis and mycophenolate mofetil. J Eur Acad Dermatol Venereol. 2008:22:631-3

139. Diab M, Coloe JR, Magro C, Bechtel MA. Treatment of recalcitrant generalized morphea with infliximab. Arch Dermatol. 2010;146:601-4.

140. Moinzadeh P, Krieg T, Hunzelmann N. Imatinib treatment of generalized localized scleroderma (morphea). J Am Acad Dermatol. 2010;63:e102-4.

141. Iñigo $F$, Jimenez-Murat $Y$, Arroyo 0 , Fernandez $M$, $Y$ sunza $A$. Restoration of facial contour in Romberg's disease and hemifacial microssomia: experience with 118 cases. Microsurgery. 2000;20:167-72.

142. Buense R, Duarte IA, Bouer M. Localized scleroderma: assessment of the therapeutic response to phototherapy. An Bras Dermatol. 2012;87:63-9.

143. El-Mofty M, Mostafa W, El-Darouty M, Bosseila M, Nada H, Yousef R, et al. Different low doses of broad-band UVA in the treatment of morphea and systemic sclerosis. Photodermatol Photoimmunol Photomed. 2004;20:148-56.
144. Kerscher M, Meurer M, Sander C, Volkenandt M, Lehmann P, Plewig G, et al. PUVA bath photochemotherapy for localized scleroderma. Evaluation of 17 consecutive patients. Arch Dermatol. 1996;132:1280-2.

145. Usmani N, Murphy A, Veale D, Goulden V, Goodfield M. Photochemotherapy for localized morphea: effect on clinical and molecular markers. Clin Exp Dermatol. 2008;33:698-704.

146. Kreuter A, Altmeyer P, Gambichler T. Treatment of localized scleroderma depends on the clinical subtype. Br J Dermatol. 2007;156:1363-5.

147. Kreuter A, Hyun J, Stücker M, Sommer A, Altmeyer P, Gambichler T. A randomized controlled study of low-dose UVA1, UVA1 medium-dose, and narrowband UVB phototherapy in the treatment of localized scleroderma. J Am Acad Dermatol. 2006;54:440-7.

148. Wu EY, Rabinovich EC, Torok KS, Li SC, Fuhlbrigge RC, CARRANet Investigators. Description of the Localized Scleroderma Subgroup of CARRA net Registry. Arthritis Rheum. 2011;63:S787-8.

149. Marsol B. Update on the classification and treatment of localized scleroderma. Actas Dermosifiliogr. 2013;104:654-66.

\author{
MAILING ADDRESS: \\ Mariana Figueiroa Careta \\ Rua Barão de Teffe 1000 sala 13 - Jardim Ana Maria \\ 13208-765 - Jundiai - SP \\ Brazil \\ E-mail: mfcareta@yahoo.com.br
}

How to cite this article: Careta MF, Romiti R. Localized scleroderma: clinical spectrum and therapeutic update. An Bras Dermatol. 2015;90(1):62-73. 